\title{
Avaliação e Caracterização de Tubos Fabricados com PVC Reciclado
}

\author{
Luiz Carlos G. Pennafort Jr., Frederico Rozendo da Silva, Enio Pontes de Deus \\ Laboratório de Mecânica da Fratura e Fadiga, UFC
}

\begin{abstract}
Resumo: Neste trabalho foram caracterizados dois polímeros utilizados na fabricação de tubos de PVC, tendo como diferencial o uso de resina de policloreto de vinila virgem e reciclada. O uso da resina reciclada, derivada do reprocessamento de resíduos aterrados (sanitários ou industriais), foi avaliado com o objetivo de compará-la a produtos fabricados com resina virgem, os quais foram submetidos aos ensaios de Fluorescência de Raios X (FRX), Difração de Raios X (DRX) e resistência à tração e alongamento. Os resultados demonstraram que houve alteração estatisticamente significativa, conforme ANOVA (5\%), nas características mecânicas do produto final, tendo os tubos fabricados com PVC reciclado apresentado uma resistência mecânica menor que os fabricados com resina virgem, além da presença de metais pesados como $\mathrm{Pb}$ (chumbo) e $\mathrm{Cd}$ (cádmio).
\end{abstract}

Palavras-chave: $P V C$ reciclado, propriedades mecânicas, difração de raios- $X$.

\section{Evaluation and Characterization of Manufactured Pipes with Recycled PVC}

Abstract: In this study two polymers used in the manufacture of PVC pipes were characterized, which differed by the use of virgin and recycled polyvinyl chloride resins. The recycled resin derived from grounded residues (sanitary or industrial) was evaluated in order to compare it with products made from virgin resin, which were subjected to testing with X-Ray Fluorescence (XRF), X-Ray Diffraction (XRD) and measurements of tensile strength and elongation. The results showed statistically significant differences in mechanical properties of the final product, according ANOVA (5\%), where pipes made from recycled PVC presented a lower mechanical strength than those made with virgin resin, in addition to containing heavy metals such as $\mathrm{Pb}$ (lead) and $\mathrm{Cd}$ (cadmium).

Keywords: Recycled PVC, mechanical properties, X-ray diffraction.

\section{Introdução}

A reciclagem de materiais de um modo geral vem se desenvolvendo de forma promissora, devido aos crescentes movimentos ecológicos nos países desenvolvidos visando poupar e preservar os recursos naturais, aliado a necessidade de se desviar os resíduos aterrados (sanitários ou industriais), reduzindo com isso, os problemas ambientais e de saúde pública, assim como os econômico-sociais decorrentes da disposição inadequada de resíduos sólidos ${ }^{[1-4]}$.

O Brasil gera diariamente em torno de 228.500 toneladas diárias de resíduos sólidos, isso significa uma produção de $1,2 \mathrm{~kg} /$ habitante $^{[5]}$. Estudos estimam que 15 a $20 \%$ correspondam em volume de materiais plásticos, sendo composto principalmente por PE (Polietileno), PET (Polietileno Tereftalato), PVC (Policloreto de Vinila) e PP (Polipropileno) ${ }^{[6]}$. O PVC material amorfo e inteiramente reciclável, é o segundo termoplástico mais consumido em todo o mundo ${ }^{[6,7]}$ onde cerca de $65 \%$ do consumo nacional são direcionados à construção civil para a fabricação de tubos, conexões, perfis, fios e cabos $^{[8,9]}$ e desta quantidade $15 \%$ são perdidas, representando o plástico predominante nos resíduos da construção civil ${ }^{[8,10]}$. No entanto, com relação a representatividade do PVC em quantidade porcentual de polímeros presentes nos resíduos sólidos urbanos das principais cidades brasileiras chega a ocupar a quarta posição ${ }^{[8]}$, ou até mesmo a segunda ${ }^{[6,11,12]}$, dependendo do ano e/ou da região da pesquisa.

A reciclagem do PVC é derivada do reprocessamento de materiais desprezados ou descartados pelos seus geradores, onde são coletados, separados e processados, e novamente transformado em matéria-prima, não sendo uma novidade, pois ela acontece desde o começo da sua produção, onde os resíduos industriais, como aparas provenientes do processo de conformação ou de corte e usinagem, produtos fora de especificação ou com defeito, descartes produzidos em partidas de máquinas, são normalmente moídos e incorporados novamente ao processo produtivo ${ }^{[13,14]}$.

Entretanto, estudos mostram que resíduos poliméricos em aterros sanitários podem sofrer degradação por termo-oxidação, fotodegradação e/ou ação microbiana ${ }^{[6]}$ acarretando mudanças em suas propriedades, estas modificações também podem ocorrer durante a operação de reciclagem, resultado de alterações estruturais, tais como: cisão da cadeia principal, reações de reticulação, mudanças na estrutura química e degradação ou eliminação dos aditivos presentes ${ }^{[15-17]}$.

Apesar da conscientização ecológica, o material plástico reciclado apresenta uma imagem distorcida, em relação ao polímero virgem, por vários fatores, que podem conduzir à desconfiança quanto ao desempenho

Autor para correspondência: Luiz Carlos G. Pennafort Jr., Laboratório de Mecânica da Fratura e Fadiga, Universidade Federal do Ceará - UFC, Campus Universitário do Pici, Bloco 714, CEP 60440-554, Fortaleza, CE, Brasil, e-mail: luizpennafortjr@gmail.com 
do reciclado: plásticos reciclados geralmente vêm de origem desconhecida, podem ter passados por processos de degradação, e ainda ter sido contaminados durante o uso anterior ${ }^{[1,18]}$.

Em geral, as indústrias de reciclagem são caracterizadas por um baixo grau de conhecimento sobre as propriedades inerentes aos seus produtos poliméricos, o que torna difícil para este segmento industrial competir com os fabricantes de polímeros virgens que por sua vez podem avaliar fiavelmente as propriedades dos seus materiais sintetizados ${ }^{[18]}$.

Diante deste contexto surge a proposta de uma ampla investigação sobre as propriedades e características desses materiais reciclados, tendo em vista a clara necessidade de um conceito de qualidade na atividade de reciclagem de plásticos, para avaliar as propriedades de materiais reciclados dentro de tolerâncias estreitas, satisfazendo assim os requisitos de ambos os fabricantes e clientes, de forma a garantir o desempenho de produtos reciclados em um mercado de segunda aplicação ${ }^{[18]}$. Para isso foram realizados testes e ensaios de caracterização de tubos fabricados a partir do PVC reciclado e da resina virgem, sendo este último avaliado com o intuito de servir como parâmetro.

\section{Materiais e Metodologia Experimental}

\section{PVC reciclado}

Uma vez separado através de triagem manual (Figura 1a) o PVC oriundo de diversas fontes (aterro, construção civil, etc.) adquiridos de cooperativas de reciclagem, foi reprocessado por reciclagem mecânica, processo que ainda figura como o mais utilizado no Brasil $^{[1]}$, seguindo as etapas de lavagem, secagem e moagem (Figuras 1b), originando a matéria-prima, Figura 1c.

Antes de ser obtido o tubo rígido de PVC reciclado, o resíduo de PVC micronizado (matéria-prima) sofreu a incorporação de aditivos no misturador, formando o composto. Uma vez preparado o composto de formulação padrão apresentada na Tabela 1, baseada nas práticas comuns dos transformadores de perfis rígidos de $\mathrm{PVC}^{[19,20]}$ e o informado pelo fornecedor dos aditivos, o mesmo foi inserido na extrusora $L G M T 75 \mathrm{Mm}$ monorosca, responsável pela gelificação, plastificação e homogeneização do composto, com temperatura de processamento por extrusão variando de 135 a $170{ }^{\circ} \mathrm{C}$, que na forma fundida alimentou a matriz, onde foi realizada a conformação do material na forma de produto final.

\section{Caracterização do material}

\section{Fluorescência de Raios-X (FRX)}

As amostras, cerca de $50 \mathrm{mg}$ na forma de pó dos tubos de $\mathrm{PVC}$ reciclado (PVCR) e de tubos de PVC de primeira linha, matéria-prima virgem (PVCV), comprados de um fabricante já conceituado no mercado, foram analisadas por um espectrômetro de fluorescência de raios-X no Laboratório de Raios-X - LRX do departamento de Física da Universidade Federal do Ceará no equipamento ZSXMini II - Rigaku para quantificação de elementos do F (Flúor) ao U (Urânio).

A técnica de FRX foi aplicada com o objetivo principal de determinar a constituição química nas amostras, método que consiste em um espectro de fluorescência de raios-X capaz de detectar a presença de átomos que participam de moléculas de aditivos, cargas, etc., permitindo sua determinação qualitativa e quantitativa $^{[21]}$.

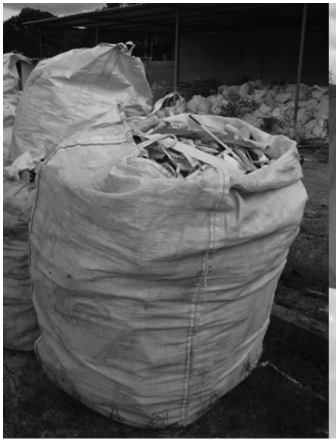

(a)

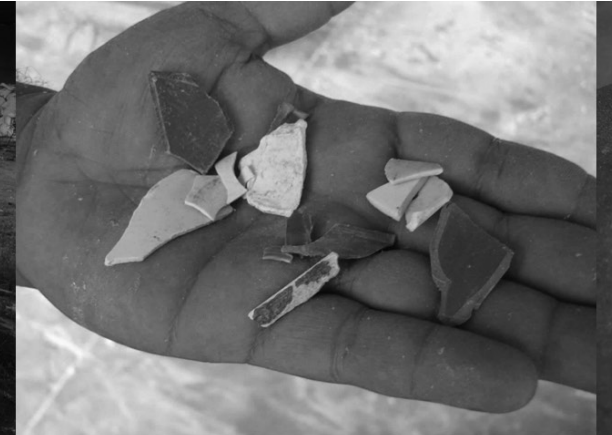

(b)

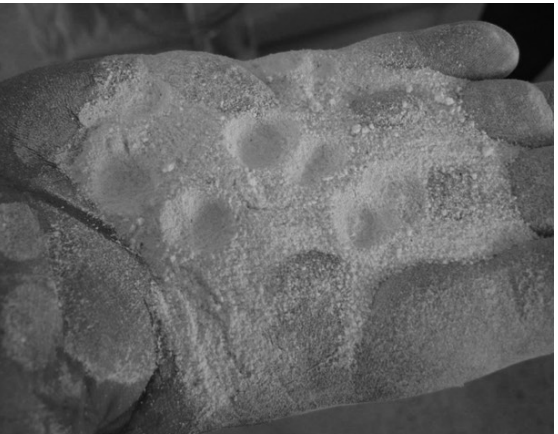

(c)

Figura 1. Reciclagem mecânica. a) Fardos com resíduos de PVC separados; b) $1^{\circ}$ moagem - moinho de facas; e c) resíduo de PVC após moinho de martelo e micronizador.

Tabela 1. Formulação do composto padrão utilizada no experimento.

\begin{tabular}{lcll}
\hline \multicolumn{1}{c}{ Componente } & Dosagem $($ pcr*) & \multicolumn{1}{c}{ Fornecedor } & \multicolumn{1}{c}{ Função na formulação } \\
\hline PVC reciclado & 100 & Recicladores (Cooperativas) & Resina de PVC reciclado \\
Baeropan ${ }^{\circledR}$ & 2,65 & Baerlocher do Brasil S.A. & Estabilizante térmico \\
Baerolub ${ }^{\circledR}$ & 0,95 & Baerlocher do Brasil S.A. & Lubrificante \\
Ti-Pure ${ }^{\circledR}$ R-102 & 2 & DuPont & Pigmento (Branco) \\
\hline
\end{tabular}

*partes por cem partes de resina de PVC. 


\section{Difração de Raios-X (DRX)}

Duas amostras foram enviadas para a difração de Raios-X: PVC reciclado (PVCR) e de PVC fabricado a partir de matéria-prima virgem (PVCV). Esta técnica utiliza o espalhamento coerente da radiação $\mathrm{X}$, por estruturas organizadas, permitindo assim realizar estudos morfológicos dos materiais ${ }^{[21]}$.

A difração foi feita no equipamento Panalytical X'Pert Pro MPD equipado com um tubo de Cobalto no intervalo de $40^{\circ}$ a $120^{\circ}$, no Laboratório de Raios-X - LRX do departamento de Física da Universidade Federal do Ceará e a identificação das fases foram feitas utilizando-se o programa PANalytical X'Pert HighScore Plus.

\section{Ensaios mecânicos}

Foram produzidos pelos métodos de corte e usinagem, corpos de prova na forma de "halteres" retirados diretamente de tubos rígidos de PVC, com base na norma ASTM D638 - Standard Test Method for Tensile Properties of Plastics, sendo 05 corpos de prova do tubo de PVC reciclado (PVCR) processado por extrusão e 05 do tubo adquirido no mercado, fabricado por uma empresa já conceituada no ramo de tubos a partir do composto de PVC virgem (PVCV).

$\mathrm{O}$ ensaio de tração foi realizado de maneira totalmente computadorizada, utilizando-se a máquina de ensaio modelo EMIC, com velocidade de deslocamento de $5 \mathrm{~mm} / \mathrm{min}$, célula de carga com capacidade máxima de até $100 \mathrm{kN}$

\section{Resultados e Discussões}

\section{Resultados da Fluorescência de Raios-X (FRX)}

Os resultados de fluorescência de raios- $X$ a seguir foram obtidos a partir dos compostos de PVC virgem e reciclado, Tabela 2.

Em ambas as amostras foram encontrados o elemento Ti, substância derivada do dióxido de titânio $\left(\mathrm{TiO}_{2}\right)$, hoje, o pigmento branco mais importante utilizado na indústria do plástico ${ }^{[20]}$.

Entretanto, no PVC reciclado(PVCR), o ensaiorevelou a presença de metais pesados $\mathrm{Pb}$ (chumbo) e $\mathrm{Cd}$ (cádmio),

Tabela 2. Fluorescência de Raios- $X$ dos tubos fabricados com PVC virgem (PVCV) e reciclado (PVCR).

\begin{tabular}{cccc}
\hline Elemento & $\begin{array}{c}\text { Massa PVCV } \\
(\boldsymbol{\%})\end{array}$ & Elemento & $\begin{array}{c}\text { Massa PVCR } \\
(\boldsymbol{\%})\end{array}$ \\
\hline $\mathrm{Cl}$ & 78,172 & $\mathrm{Cl}$ & 71,712 \\
$\mathrm{Ca}$ & 18,547 & $\mathrm{Ca}$ & 21,377 \\
$\mathrm{Ti}$ & 1,099 & $\mathrm{Ti}$ & 3,550 \\
$\mathrm{Si}$ & 0,577 & $\mathrm{~Pb}$ & 2,263 \\
$\mathrm{Al}$ & 0,386 & $\mathrm{Si}$ & 0,496 \\
$\mathrm{Zn}$ & 0,336 & $\mathrm{Cd}$ & 0,237 \\
$\mathrm{~K}$ & 0,335 & $\mathrm{Zn}$ & 0,219 \\
$\mathrm{Fe}$ & 0,209 & $\mathrm{~K}$ & 0,146 \\
$\mathrm{Ag}$ & 0,197 & & \\
$\mathrm{P}$ & 0,088 & & \\
$\mathrm{~S}$ & 0,055 & & \\
\hline
\end{tabular}

elementos muito usados no passado como estabilizante, porém, considerados tóxicos e não permitidos para compostos destinados a entrar em contato com alimentos e em brinquedos ${ }^{[14]}$, elementos estes que provavelmente surgiram na amostra devido a contaminação do composto micronizado, tendo em vista que o material utilizado na reciclagem tem origem de diversas fontes como aterros sanitários, construção civil, etc.

A substituição dos estabilizantes térmicos destinados à fabricação de tubos, produzidos com metais pesados, como o chumbo, é um contexto que vem sendo tratado há alguns anos, tendo os estabilizantes à base de cálciozinco como alternativa ${ }^{[22]}$, fato confirmado no resultado obtido para o composto do tubo de PVC virgem (PVCV).

Há também a possibilidade dos materiais poliméricos utilizados na reciclagem terem entrado em contato com impurezas e contaminantes a partir do ambiente circundante durante a sua utilização, que podem difundir-se na estrutura polimérica devido à sua natureza permeável ${ }^{[18]}$.

\section{Análise difratométrica}

Os difratogramas referentes às amostras PVCV (resina virgem) e PVCR (reciclado), ilustrados nas Figuras 2 e 3 , em 2 teta para aproximadamente 35 graus, sobressaem-se picos cristalinos referente ao carbonato de cálcio ${ }^{[23]}$.

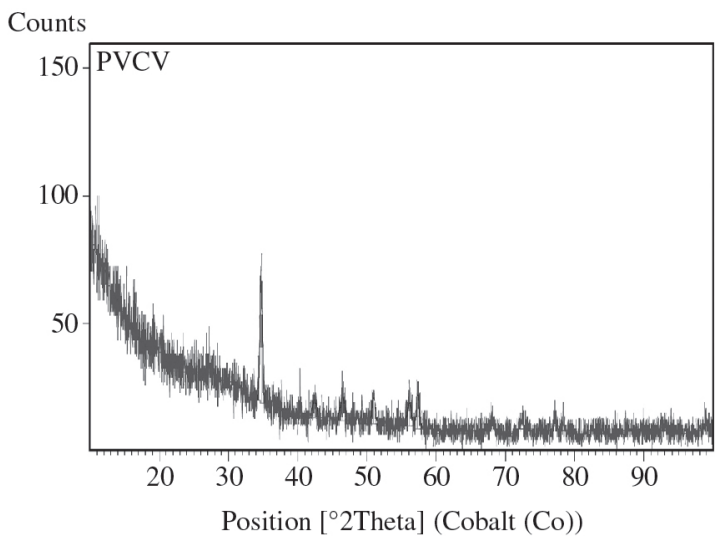

Figura 2. Difratograma de raios-X da amostra de PVCV - resina virgem.

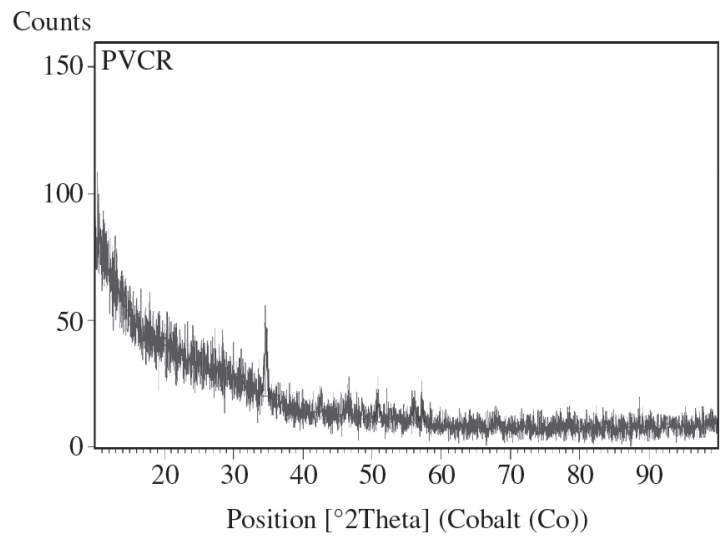

Figura 3. Difratograma de raios- $X$ da amostra de PVCR - reciclado. 


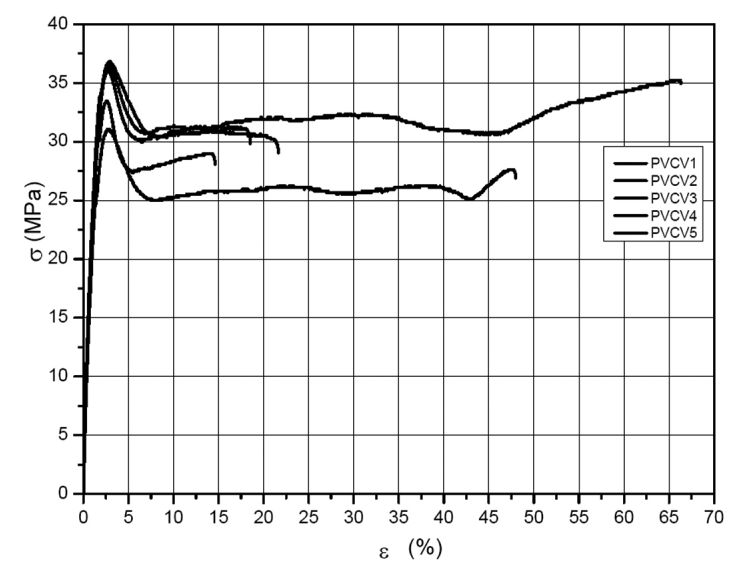

Figura 4. Gráfico tensão $\times$ deformação para corpos de prova de PVCV.

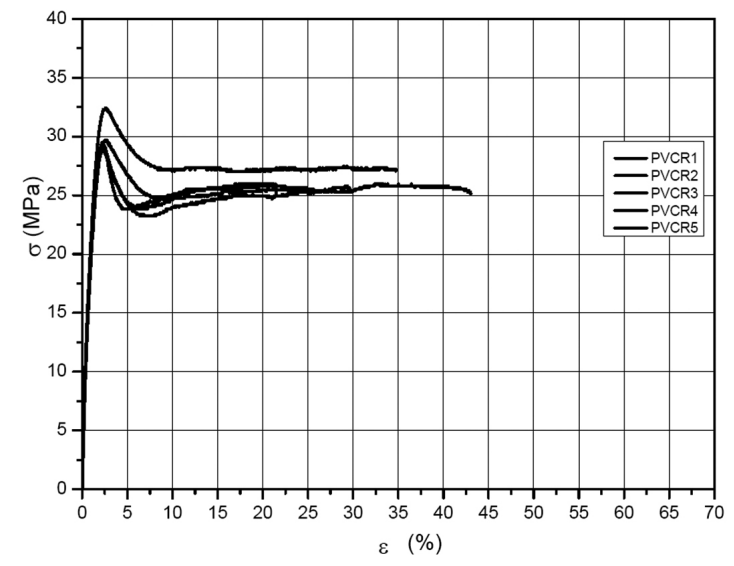

Figura 5. Gráfico tensão x deformação para corpos de prova de PVCR.

Tabela 3. Propriedades mecânicas obtidas do ensaio de tração.

\begin{tabular}{ccccccc}
\hline Material & Tensão Máxima & $\begin{array}{c}\text { Tensão de } \\
\sigma_{\text {max }}(\mathbf{M P a})\end{array}$ & $\begin{array}{c}\text { Tensão de } \\
\text { Ruptura } \\
\sigma_{\text {esc }}(\mathbf{M P a})\end{array}$ & $\begin{array}{c}\text { Deformação } \\
\text { na } \sigma_{\text {rup }}(\mathbf{m m})\end{array}$ & $\begin{array}{c}\text { Módulo de } \\
\text { Elasticidade E } \\
(\mathbf{M P a})\end{array}$ \\
\hline \multirow{2}{*}{ PVCV } & Média & 34,8 & 34,8 & 29,7 & 38,9 & 3061,2 \\
& Desvio & 2,5 & 2,5 & 3,1 & 25,8 & 280,8 \\
\hline \multirow{2}{*}{ PVCR } & Média & 29,9 & 29,9 & 25,6 & 35,5 & 2890,6 \\
& Desvio & 1,4 & 1,4 & 0,9 & 9,6 & 99,4 \\
\hline
\end{tabular}

A presença do carbonato de cálcio $\left(\mathrm{CaCO}_{3}\right)$ nas amostras demonstra o uso desta substância como carga, utilizada com o objetivo de reduzir o custo do composto, proporcionar bom acabamento superficial e alto brilho, aumentar a resistência mecânica e às intempéries, e melhorar a estabilidade dimensional a elevadas temperaturas ${ }^{[20]}$.

\section{Propriedades mecânicas}

Os resultados dos ensaios de tração são apresentados nas Figuras 4 e 5, onde o programa Mtest, software conectado a máquina de ensaio, forneceu os valores das tensões máxima $\left(\sigma_{\max }\right)$, de escoamento $\left(\sigma_{\text {esc }}\right)$ e de ruptura $\left(\sigma_{r u p}\right)$, além da deformação na tensão de ruptura e o módulo de elasticidade $(E)$, resultados que estão apresentados na Tabela 3.

Os dados dos ensaios foram submetidos à análise de variância (ANOVA), o nível de significância de 95\% e os resultados evidenciam-se na Tabela 4. Observou-se que, nesse caso apesar das diferenças acima expostas, a deformação até a ruptura e o módulo de elasticidade $(E)$ não demonstraram diferenciação estatística significativa (valor-P > 0,05) entre os dois polímeros.

Entretanto, pode-se verificar que o PVCV obteve maiores médias nas tensões máxima, de escoamento e de ruptura, comparativamente ao PVCR, diferença essa que mostrou-se estatisticamente significativa, conforme ANOVA (5\%).

Diante dos resultados apresentados notou-se que o PVC reciclado apresentou propriedades bem próximas a do PVC fabricado a partir da resina virgem, porém com resistência mecânica mais baixa, confirmando o apresentado por diversos estudos sobre o processo de
Tabela 4. Análise de variância (ANOVA) para as propriedades mecânicas (probabilidade: 0,05).

\begin{tabular}{lccc}
\hline \multicolumn{1}{c}{ Propriedades } & $\mathbf{F}$ & valor-P & $\mathbf{F}_{\text {crítico }}$ \\
\hline$\sigma_{\text {max }}($ Mpa)PVCR1 & 14,5320 & 0,0051 & 5,3177 \\
$\sigma_{\text {esc }}$ & 14,5320 & 0,0051 & 5,3177 \\
$\sigma_{\text {rup }}$ & 8,0521 & 0,0219 & 5,3177 \\
Def. na $\sigma_{\text {rup }}(\mathrm{mm})$ & 0,0746 & 0,7917 & 5,3177 \\
$E$ & 1,6408 & 0,2361 & 5,3177 \\
\hline
\end{tabular}

reciclagem mecânica por extrusão convencional de material oriundo de resíduos plásticos urbanos, onde a degradação anterior provoca uma deterioração da estrutura molecular, resultando em plásticos reciclados com propriedades mecânicas mais pobres do que as virgens, se manifestando principalmente através da diminuição da resistência à tração na ruptura e do módulo elástico $^{[18,24]}$.

Outro fator de grande influência nas propriedades mecânicas é a quantidade de carga no composto, situação comprovada nos resultados de fluorescência de raios-X, onde o composto de PVC reciclado apresentou uma quantidade maior de cálcio, elemento oriundo do carbonato de cálcio $\left(\mathrm{CaCO}_{3}\right)$, pois a interface carga/matriz tem papel fundamental nas propriedades mecânicas finais do produto, tendo em vista o tipo de adesão existente entre o $\mathrm{CaCO}_{3}$ e o PVC ser mecânica, que não sendo perfeita, surgem vazios que provocam a fragilização do material ${ }^{[2]}$.

\section{Conclusões}

As amostras de polímero reciclado foram identificadas como Policloreto de Vinila (PVC) adicionado de carbonato de cálcio - $\mathrm{Ca}\left(\mathrm{CO}_{3}\right)$, substância muito usada como aditivo de carga, tendo como função principal a redução no preço 
dos compostos, porém os testes identificaram quantidades acima do utilizado na fabricação de tubos comerciais.

Outros elementos presentes em quantidade elevada nas amostras de PVCR que chamaram a atenção foram o chumbo $(\mathrm{Pb})$ substância encontrada em alguns estabilizantes e responsável por conferir ao produto final uma boa opacidade, resistência térmica e baixo custo, e o titânio $(\mathrm{Ti})$, na forma de dióxido de titânio $\left(\mathrm{TiO}_{2}\right)$ sendo hoje o pigmento branco mais importante utilizado na indústria do plástico ${ }^{[20]}$.

As propriedades mecânicas do PVC reciclado se mostraram inferiores devidos suas propriedades serem modificadas durante a reciclagem, pois durante o reprocessamento com reciclagem mecânica a resina passa por um novo ciclo de aquecimento, facilitando a degradação térmica ao prejudicar a estabilidade das ligações $\mathrm{C}-\mathrm{Cl}$, resultando na saída de ácido clorídrico da cadeia, formando duplas ligações $\mathrm{C}=\mathrm{C}^{[25-27]}$.

Diante dos resultados obtidos ficou evidente que a reciclagem do PVC é promissora, pois os valores se mostraram bem próximos aos do PVC virgem, sendo possível com alguns ajustes na composição final produzir produtos com características semelhantes aos que utilizam matéria-prima virgem, entretanto, a identificação de contaminantes, aditivos e produtos de degradação presentes nos polímeros reciclados é essencial para assegurar que os produtos sejam compatíveis com a legislação sobre a presença de substâncias perigosas ${ }^{[18]}$, já que a norma NBR 5688 proibe a fabricação de tubos e conexões de PVC a partir de material reciclado pós-consumo.

\section{Referências Bibliográficas}

1. Piva, A. M.; Bahiense Neto, M. \& Wiebeck, H. - Polímeros, 9, 4. p.195 (1999).

2. Yoshiga, A.; Toffoli, S. M. \& Wiebeck, H. - Polímeros, 14, p.134 (2004). http://dx.doi.org/10.1590/S010414282004000300007

3. Da Cruz, A. L. M. - "A reciclagem dos resíduos sólidos urbanos: um estudo de caso", Dissertação de Mestrado, Universidade Federal de Santa Catarina, Brasil (2003).

4. Gunther, W. R. - "Resíduo Sólido Urbano", in: Tecnologia de Reciclagem do Plástico, ATUALTEC/CECAE-USP, São Paulo, Apostila do curso de Reciclagem de Plásticos (1996).

5. Mucelin, C. A. \& Bellini, M. - Soc. Nat., 20, p.111 (2008). http://dx.doi.org/10.1590/S1982-45132008000100008

6. Grisa, A. M. C.; Simioni, T.; Cardoso, V.; Zeni, M.; Brandalise, R. N. \& Zoppas, B. C. D. A. - Polímeros, 21, p.210 (2011). http://dx.doi.org/10.1590/S010414282011005000046

7. Rodolfo Junior, A. \& Mei, L. H. I. - Polímeros, 17, p.263 (2007). http://dx.doi.org/10.1590/S010414282007000300018

8. Mancini, S. D.; Darbello, S.; Schwartzman, J. ; Kagohara, D.; Nogueira, A.; Keiroglo, R.; Franco, C.; Mantovani, V. \& Wiebeck, H. - "Caracterização dos resíduos da construção civil de Sorocaba - SP com ênfase em plásticos", in: Anais $9^{\circ}$ Congresso Brasileiro de Polímeros (2007)

9. Associação Brasileira da Indústria Química - Anuário Brasileiro da Indústria Química (2005).
10. Daltro Filho, J.; Bandeira, A. A.; Barreto, I. M. C. B. N. \& Agra, L. G. S. - "Avaliação da composição e quantidade dos resíduos sólidos da construção civil de AracajuSergipe-Brasil", in: VIII Simpósio Ítalo Brasileiro de Engenharia Sanitária e Ambiental (2006).

11. Spinacé, M. A. S. \& De Paoli, M. A. - Quim. Nova, 28, p.65 (2005). http://dx.doi.org/10.1590/S010040422005000100014

12. Vinhas, G. M.; Souto-Maior, R. M. \& De Almeida, Y. M. B. - Polímeros, 15, p.207 (2005). http://dx.doi.org/10.1590/ S0104-14282005000300011

13. Bonelli, C. M. C.; Elzubair, A.; Suarez, J. C. M. \& Mano, E. B. - Polímeros, 15, p.256 (2005). http://dx.doi.org/10.1590/ S0104-14282005000400009

14. Wiebeck, H. \& Piva, M. A. - "Reciclagem mecânica do PVC", Instituto do PVC, CD-ROM (2001).

15. Rabello, M. - "Aditivação de Polímeros", Editora Artliber, São Paulo (2000).

16. Mählmann, C. M.; Rodríguez, A. L.; López, D. A. R.; Niedersberg, C.; Teixeira, D. B. \& Kipper, L. M. - "Influence of multiple extrusion on mechanical properties of high-density polyethylene (HDPE)", in: $17^{\circ}$ CBECIMat - Congresso Brasileiro de Engenharia e Ciência dos Materiais, Foz do Iguaçu, PR, Brasil 2006.

17. Sombatsompop, N. \& Thongsang, S. - J. Appl. Polym Sci., 82, p.2478 (2001). http://dx.doi.org/10.1002/app.2098

18. Vilaplana, F. \& Karlsson, S. - Macromol. Mater. Eng., 293, p.274 (2008). http://dx.doi.org/10.1002/mame.200700393

19. Feltran, M. B. \& Diaz, F. R. V. - Polímeros, 17, p.276 (2007). http://dx.doi.org/10.1590/S0104-14282007000400005

20. Rodolfo Junior, A.; Nunes, L. R. \& Ormanji, W. - "Tecnologia do PVC", 2. ed., ProEditores Associados, São Paulo (2006).

21. Canevarolo Junior, S. V. - "Técnicas de caracterização de polímeros", Artiliber editora, São Paulo (2004)

22. De Almeida, D. V. \& Matsumoto, H. - "Substituição do Estabilizante a base de chumbo pelo de cálcio/zinco no processo produtivo de tubos de PVC rígido", in: $17^{\circ}$ CBECIMat - Congresso Brasileiro de Engenharia e Ciência dos Materiais, Foz do Iguaçu, PR, Brasil (2006)

23. Campos, J.; Ribeiro, A. \& Cardoso, C. - Materials Science and Engineering B, 136, p. 123 (2007).

24. Alcântara, R. L.; Carvalho, L. H. \& Ramos, S. M. L. S. - Polímeros, 5, p.42 (1995)

25. Prestes, S. M. D.; Mancini, S. D.; Rodolfo Junior, A.; Cruz, N. C.; Rangel, E. C. \& Keiroglo, R. C. - "Tubos de PVC pós-consumo reciclados mecanicamente: influência da granulometria na reciclagem e em propriedades finais", in: Anais $10^{\circ}$ Congresso Brasileiro de Polímeros (2009).

26. De Paoli, M. A. - "Degradação e estabilização de polímeros", 2. ed., Chemkeys (2008)

27. Grisa, A. M. C.; Kauling, A. P. \& Zeni, M. - "Avaliação da degradação do poli(cloreto de vinila) (PVC) no meio ambiente", in: Anais $9^{\circ}$ Congresso Brasileiro de Polímeros (2007)

Enviado: $15 / 03 / 12$ Reenviado: $30 / 08 / 12$ Aceito: 06/09/12 